\title{
Possibilidades e limites das tecnologias na Educação Infantil: um olhar sobre as teses e dissertações dos anos de 2006 a 2016
}

\author{
Hélida Cristina Brandão Nunes
}

Robson Luiz de França²

Resumo: Este artigo descreve uma pesquisa que teve o objetivo de investigar as teses e dissertações desenvolvidas nos anos de 2006 a 2016, com o propósito de analisar as possibilidades das tecnologias, os limites e sua articulação à prática pedagógica infantil. Os resultados revelaram que o computador foi o recurso mais discutido e estava relacionado aos laboratórios de informática na maioria dos estudos. As possibilidades ressaltadas foram o enriquecimento do processo de ensino-aprendizagem, crescimento do interesse, da autonomia, do trabalho colaborativo com ampliação de novas linguagens e a possibilidade do letramento digital. Contudo, os limites salientaram dificuldades de suporte técnico, problemas de conexão com a rede de Internet, de aquisição de recursos mais atuais, bem como qualificação profissional, ressaltada na maioria dos trabalhos.

Palavras-chave: Possibilidades. Limites. Tecnologias. Educação Infantil.

Abstract: This article describes a research that had the objective to investigate the theses and dissertations developed in the years 2006 to 2016, with the purpose of analyzing the possibilities of the technologies, the limits and its articulation to the pedagogical practice of children. The results revealed that the computer was the most discussed resource and was related to computer labs in most studies. The possibilities highlighted were the enrichment of the teaching-learning process, growth of interest, autonomy, collaborative work with the expansion of new languages and the possibility of digital literacy. However, the limits highlighted technical support difficulties, connection problems with the Internet network, acquisition of more current resources, as well as professional qualification, highlighted in most of the works.

Keywords: Possibilities. Limits. Technologies. Child education.

Resumen: Este artículo describe una investigación que tuvo el objetivo de investigar las tesis y disertaciones desarrolladas en los años 2006 a 2016, con el propósito de analizar las posibilidades de las tecnologías, los límites y su articulación a la práctica pedagógica infantil. Los resultados revelaron que el ordenador fue el recurso más discutido y estaba relacionado con los laboratorios de informática en la mayoría de los estudios. Las posibilidades resaltadas fueron el enriquecimiento del proceso de enseñanza-aprendizaje, crecimiento del interés, de la autonomía, del trabajo colaborativo con ampliación de nuevos lenguajes y la posibilidad del letramento digital. Sin embargo, los límites resaltaron dificultades de soporte técnico, problemas de conexión con la red 
de Internet, de adquisición de recursos más actuales, así como calificación profesional, resaltada en la mayoría de los trabajos.

Palabras claves: Posibilidades. Límites. Tecnologías. Educación Infantil.

\section{Introdução}

Ao considerar as transformações culturais, científicas e tecnológicas na sociedade contemporânea, verifica-se que os recursos tecnológicos, ao serem utilizados de forma articulada e coerente com o processo de ensino-aprendizagem, podem trazer benefícios em relação à comunicação, à cooperação e à aprendizagem dos educandos. Inclusive em relação às crianças da Educação Infantil, que estão em contato cada vez mais precoce com os meios tecnológicos e imersos no mundo digital devido à utilização cada vez mais acentuada das Tecnologias da Informação e Comunicação (TICs).

Sob essa ótica, devido ao mundo virtual está constantemente presente na vida das crianças, há exigência de mudanças das instituições escolares, instigando novos olhares para os desafios tecnológicos que permeiam a prática pedagógica, bem como uma Formação Continuada profissional para lidar com o novo contexto que se apresenta. Isso se torna necessário para promover a reflexão sobre o trabalho cotidiano e transformar as estratégias educacionais em percursos diferenciados, interessantes e construtivos, de acordo com as necessidades infantis. Por ser um período com necessidade de estimulação e desenvolvimento dos requisitos essenciais para um crescimento integral da criança, visto ser a base da infância.

\section{As tecnologias e a Educação Infantil}

A sociedade contemporânea está permeada de mudanças que requerem uma educação capaz de preparar o educando para agir com autonomia, criatividade e criticidade, diante das novas situações globais. O processo educativo deixa de ser, então, um mero sinônimo de transmissão de conhecimentos e informações para ter um caráter de construção e de renovação educativa constante.

Nesse sentido, as instituições escolares diante dos desafios tecnológicos, precisam relevar as mudanças sociais, culturais, científicas, políticas, econômicas das novas gerações, que segundo Tapscott (2010) estão precocemente imersas no mundo tecnológico, fazendo parte da "Geração digital". Desse modo, Sodré (2012, p. 12) afirma que é necessário ressignificar a educação, porque "[...] todo e qualquer projeto educacional se obriga a pensar e agir em sintonia com as exigências postas pela tecnologização do mundo e com as injunções do mercado global". Isso exige uma "reeducação" social de forma dinâmica e crítica, considerando a diversidade temporal e espacial de seus sujeitos. Nesse processo de reinvenção, é importante que o docente se aproprie de um leque de saberes que emergem junto às tecnologias, sobretudo às Tecnologias da Informação e Comunicação (TICs), visando integrá-la à prática pedagógica.

De acordo com dados do Centro de Estudos sobre as Tecnologias da Informação e da Comunicação (CETIC) que realizam pesquisas sobre o desenvolvimento da Internet no país, os meios tecnológicos estão presentes em grande parcela da população pesquisada, conforme é demonstrado no Gráfico 1: 


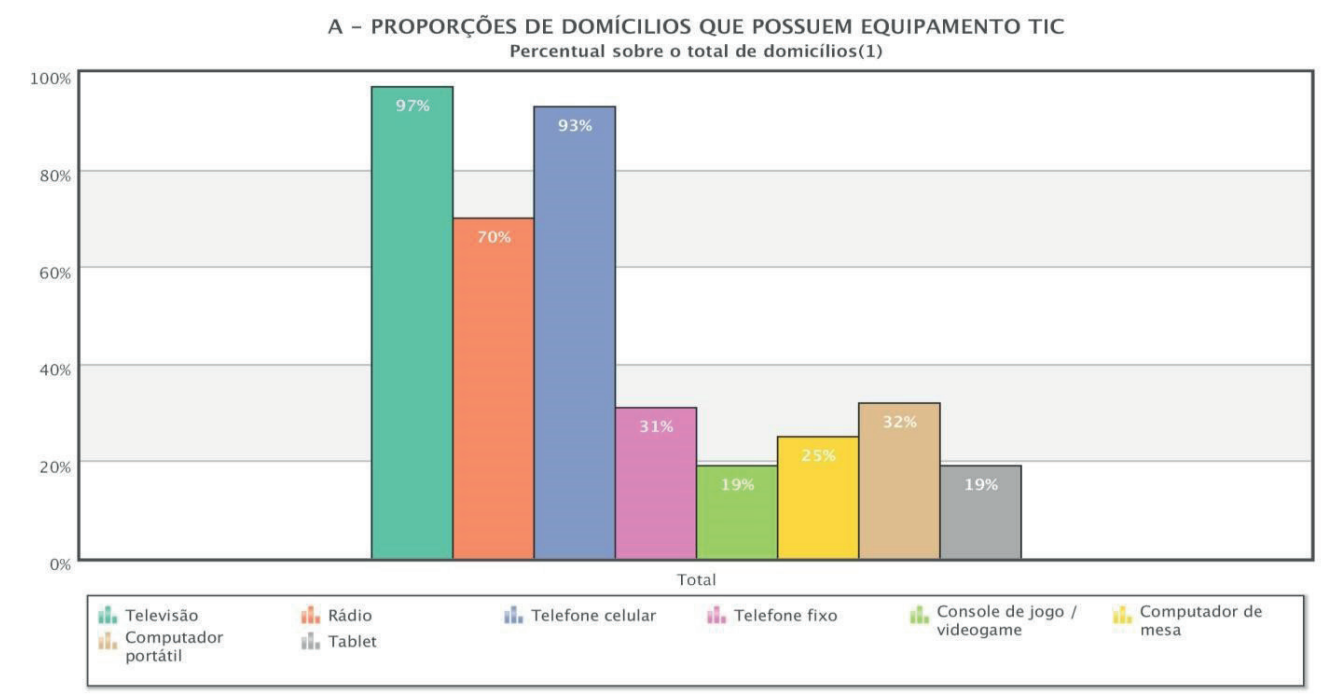

Percentual sobre o total de domicilios

(1) Base: 67.038 .766 domicilios. Respostas mútiplas e estimuladas. Dados coletados entre Novembro de 2015 e J unho de 2016.

Fonte: Núcleo de Informaçăo e Coordenaçăo do Ponto BR (NIC.br).

Fonte: CETIC (BRASIL, 2017)

O estudo realizado por essa instituição (BRASIL, 2017), constata que a maioria dos domicílios da população brasileira entrevistada possui televisão (97\%) e celular (93\%). Segundo CETIC, uma parcela de 25\% dos entrevistados possuem computador de mesa e 32\%, o portátil, contudo, 61\% dos usuários já utilizaram um computador (BRASIL, 2017). Os dados demonstram que são 78\% de domicílios com acesso à Internet, nas zonas urbana (56\%) e rural (22\%), resultados que tiveram um crescimento significativo em comparação aos anos anteriores Todavia, o acesso foi limitado a 16\% nos domicílios das classes D e E, em comparação às classes C (56\%), B (88\%) e A (99\%), o que requer maior democratização desse acesso aos que ainda estão à margem desse processo. Sob essa ótica, comprovou-se que o acesso à Internet está se popularizando e o ambiente escolar poderá ser um local propício de oportunidade de ampliação e inclusão digital de todos.

De fato, a integração dos recursos tecnológicos na prática docente depende, em parte de como os profissionais compreendem esse processo de transformação e se sentem em relação a isso - se o vê como algo benéfico, que pode ser favorável ao seu trabalho, ou se sente ameaçado e acuado por essas mudanças. Conforme Kenski (2008, p. 18), nota-se que existe "o duplo desafio para a educação: adaptar-se aos avanços das tecnologias e orientar o caminho de todos para o domínio e a apropriação crítica desses novos meios". Para isso, torna-se primordial que os profissionais tenham a oportunidade de "[...] uma formação inicial sólida e consistente acompanhada de adequada e permanente atualização em serviço" (BRASIL, RCNEF, 1998, p. 41).

Por meio da tecnologia, a criança tem a oportunidade de despertar sentidos como audição, visão e tato. Entretanto, é necessário haver um limite para o contato com os meios tecnológicos, para não extrapolar no tempo e não absorvê-los de maneira acrítica. Pelo fato de a mídia envolver o sistema da comunicação, torna-se necessário identificar e utilizar suas influências nos espaços escolares e enfrentar o desafio de desenvolver a consciência crítica 
dos alunos, no que concerne aos benefícios apresentados pelas novas tecnologias (LOPES et al., 2011, p. 180).

Lopes et al. (2011) comentam ainda, que algumas escolas de Educação Infantil já fazem uso de meios multimídia como recurso pedagógico, tais como computadores conectados à Internet e distribuição de notebooks para professores e alunos. Já que independentemente da idade, entram em contato cada vez mais cedo com equipamentos tecnológicos, o que exige da escola o uso de tais meios para favorecer a construção de saberes na Educação Infantil.

Vygotsky, Luria e Leontiev (2016) destacam que a base do desenvolvimento do ser humano é resultante de um processo sócio-histórico, cuja ênfase reside no papel da linguagem e da aprendizagem. Nessa perspectiva, os autores afirmam que esse processo se realiza por meio de um mediador que poderá ser: uma pessoa mais experiente, instrumentos ou signos, a interação entre os pares, etc. E a ludicidade que é inerente à infância, não poderá ser desconsiderada, porque "a criança estabelece os diferentes vínculos entre as características do papel assumido, suas competências e as relações que possuem com outros papéis, tomando consciência disto e generalizando para outras situações" (BRASIL, RCNEF, 1998, p. 28). Assim, a interação social e a linguagem são importantes para o desenvolvimento do conhecimento que é construído socialmente.

Em uma pesquisa de Juppe (2004), realizou-se uma análise das possibilidades e dos limites dos recursos tecnológicos presentes em 14 instituições de Educação Infantil, que identificou quais os equipamentos disponíveis e como as escolas pensavam e utilizavam esses recursos. Os resultados comprovaram "[...] que depois do aparelho de som, a TV é a presença mais frequente nas escolas e por essa razão, tornou-se o equipamento evidenciado no decorrer da pesquisa" (JUPPE, 2004, p. 66). Entretanto, se observou que o acesso a essas tecnologias era quase sempre precário, os recursos insuficientes quanto à quantidade e à qualidade. O que sugeriu a necessidade de investir na formação docente (mesmo apresentando lacunas na forma como era desenvolvida), para discussão das teorias da infância e para a articulação das tecnologias à educação.

Nessa perspectiva, não basta somente a aquisição dos recursos, sem uma devida preparação ou formação continuada ou permanente dos profissionais (IMBERNÓN, 2009) para utilizá-los de forma efetiva, promovendo a emancipação de todos. Por esse motivo, o trabalho com as tecnologias exige um novo olhar para esses desafios com: mudanças de paradigmas de conceitos de infância e de Educação Infantil. É importante a organização de momentos de trocas de experiências, de formação continuada para que todos os profissionais possam se inteirar dos novos meios e consigam utilizá-los de acordo com as necessidades das crianças. E que o educador utilize sua criatividade e sua capacidade de extrair o máximo de benefícios possíveis dos recursos, orientando para o uso pedagógico de tais ferramentas, na tentativa de fugir de campos mais fúteis e capitalistas impostos por elas.

Moran et al. (2008) explicam que é necessário então, refletir sobre todo o processo, reaprender e orientar atividades, definir o que é significativo, de forma coletiva ou individual. Os autores apontam que novos campos de educação se abrem perante às novas tecnologias. Esses desafios serão tecnológicos e também pedagógicos, uma vez que, isoladamente, as tecnologias não serão capazes de modificar a educação, mas vão ser responsáveis por agregar inúmeras possibilidades de apoio ao trabalho docente. 


\section{Metodologia}

Esta investigação se desenvolveu por meio de uma pesquisa de abordagem qualitativa de revisão bibliográfica sistemática, em um estudo crítico-descritivo de teses e dissertações desenvolvidas nos anos de 2006 a 2016. O objetivo foi identificar as possibilidades, os limites e a articulação das tecnologias na prática pedagógica da Educação Infantil. Nesse contexto, o estudo se justificou pela necessidade de compreender como as tecnologias impactam a prática pedagógica infantil.

De acordo com Gil (2008, p. 50), "[...] a principal vantagem da pesquisa bibliográfica, reside no fato de permitir ao investigador, a cobertura de uma gama de fenômenos muito mais ampla do que aquela que poderia pesquisar diretamente". Estudos dessa natureza favorecem uma visão global do assunto pesquisado, para compreender as tendências de pesquisas, descobrir lacunas na área e contribuir com outros propósitos investigativos.

Sampaio e Mancini (2007) explicam que a revisão sistemática é baseada em dados da literatura disponivel sobre determinado tema e oferece um resumo acerca das evidências pesquisadas, por meio da aplicação de métodos explícitos e sistemáticos, que buscam, contemplam, criticam e sintetizam as informações encontradas.

A busca para a seleção das pesquisas foram realizadas no banco de dados da Biblioteca Digital Brasileira de Teses e Dissertações, do Instituto Brasileiro de Informação em Ciência e Tecnologia - IBICT, por ser um meio eficiente e de credibilidade.

A distinção do recorte do período selecionado (2006-2016) se deve às mudanças significativas ocorridas nos anos. Um exemplo disso se refere às mudanças no curso de licenciatura em Pedagogia com as Diretrizes Curriculares Nacionais, promulgadas em 2006 pelo ConseIho Nacional de Educação, com a Resolução CNE/CP n. 1 (BRASIL, 2006a), que modificou a estrutura do curso e definiu que os licenciados em Pedagogia exercessem somente a docência. Houve também a alteração na Lei de Diretrizes e Bases da Educação Nacional (LDBEN) (BRASIL, Lei n. 11.274/2006c), com o Ensino Fundamental de 9 anos. Em 2007, houve a criação do Fundo de Manutenção e Desenvolvimento da Educação Básica e de Valorização dos Profissionais da Educação (FUNDEB) (BRASIL, Lei n. 11.494/2007), e a regulamentação do Programa Nacional de Tecnologia Educacional (Prolnfo) com o Decreto n. 6.300 (BRASIL, 2007). Outra relevante mudança ocorreu na LDBEN em 2013 (BRASIL, Lei n. 12.796, 2013), com a inclusão da Educação Infantil na primeira etapa da educação nacional.

\section{Desenvolvimento da pesquisa}

Os procedimentos metodológicos da pesquisa de revisão sistemática se realizou em uma sequência delineada por Sampaio e Mancini (2007), por meio de cinco etapas que foram destacadas na Figura 1: 


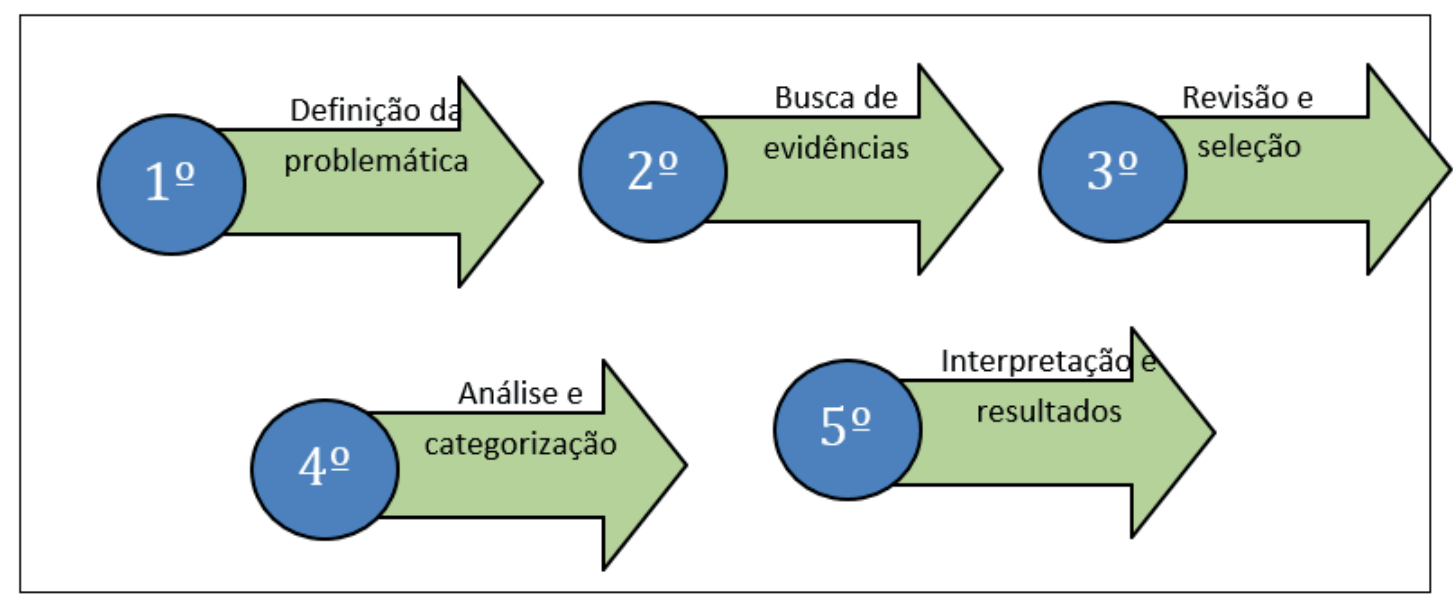

Fonte: Elaboração própria (Sampaio; Mancini, 2007).

$1^{a}$. Definição da problemática: A partir da problemática da investigação, a pesquisa foi iniciada procurando identificar e analisar as seguintes questões: quais são as tecnologias que estão relacionadas à Educação Infantil, nas teses e dissertações desenvolvidas nos anos de 2006 a 2016? De que modo as tecnologias discutidas nas pesquisas estão interligadas à prática pedagógica da infância? E quais são as possibilidades e os limites das tecnologias nos trabalhos selecionados? A partir dessas questões, segui-se para a próxima fase.

$2^{a}$. Busca de evidências: A busca das pesquisas foi realizada por meio das palavras-chave "Tecnologias" e "Educação Infantil", no site do IBICT. Os termos foram escolhidos para a seleção dos trabalhos acadêmicos, por se referirem aos objetivos deste estudo, aplicando-se filtros somente em relação ao idioma (língua portuguesa), aos anos de publicação (2006 a 2016) e ao grau da publicação separados por categorias (teses, dissertações).

Após a primeira seleção, que foi a partir dos títulos, o total de pesquisas encontradas foram 154 dissertações e 32 teses. Dentre as publicações descartadas, algumas estavam direcionadas a outros níveis de ensino ou à área da saúde, bem como referentes a discussões de aspectos sociológicos, sem relação com a tecnologia ou a Educação Infantil.

$3^{\text {a }}$. Revisão e seleção das pesquisas: Os textos foram selecionados a partir da verificação dos títulos dos trabalhos, os quais condiziam com o tema e os objetivos desta pesquisa baseados nos critérios de inclusão e exclusão. Depois, na segunda leitura, os resumos foram analisados e, se fosse necessário, o contexto das pesquisas, para não excluir estudos importantes da revisão sistemática (SAMPAIO; MANCINI, 2007).

Dessa forma, foram incluídas somente as pesquisas que se relacionaram à Educação Infantil e que tinham as tecnologias no desenvolvimento de sua prática pedagógica, suprimindo os trabalhos que não se enquadraram nesses quesitos. Após a leitura criteriosa dos 186 resumos dos trabalhos encontrados, foram selecionados de acordo com os objetivos propostos o total de 25 trabalhos (20 dissertações e 5 teses), conforme a Tabela 1.

Tabela 1. Dissertações e teses selecionadas sobre tecnologias na Educação Infantil (20062016) 


\begin{tabular}{|c|c|c|c|}
\hline ANO & AUTOR & TÍTULO & INSTITUIÇÃO \\
\hline $\begin{array}{l}2006 \\
(\mathrm{~T})\end{array}$ & ZANAGA & $\begin{array}{l}\text { Conteúdos abertos na educação: motivações e visão de } \\
\text { autoria. }\end{array}$ & UNICAMP \\
\hline 2007 (D) & MACHADO & $\begin{array}{l}\text { Um software educativo de exercício-e-prática como } \\
\text { ferramenta no processo de alfabetização infantil. }\end{array}$ & UFU \\
\hline $\begin{array}{c}2007 \\
\text { (D) }\end{array}$ & OLIVEIRA & $\begin{array}{l}\text { Tecnologias da informação no cotidiano escolar: } \\
\text { ressonância na gestão educacional - análise } \\
\text { micropolítica de uma escola em Barcelona. }\end{array}$ & UERJ \\
\hline $\begin{array}{c}2007 \\
\text { (D) }\end{array}$ & SANTOS & Computador: a máquina do conhecimento na escola. & USP \\
\hline $\begin{array}{c}2007 \\
(\mathrm{D})\end{array}$ & SCHNEIDER & $\begin{array}{l}\text { PLANETA ROODA: desenvolvendo arquiteturas } \\
\text { pedagógicas para educação infantil e anos iniciais do } \\
\text { ensino fundamental. }\end{array}$ & UFRGS \\
\hline $\begin{array}{c}2008 \\
\text { (D) }\end{array}$ & MARCONATTO & $\begin{array}{l}\text { "Uma brincadeira para a infância": uma proposta que } \\
\text { inclui a linguagem de imagem e som para a produção } \\
\text { infantil. }\end{array}$ & UNICAMP \\
\hline $\begin{array}{l}2009 \\
\text { (D) }\end{array}$ & MACHADO & $\begin{array}{l}\text { Reflexões sobre a vivência no "cantinho do notebook" } \\
\text { em uma turma de educação infantil. }\end{array}$ & UTFPR \\
\hline $\begin{array}{c}2009 \\
(\mathrm{~T})\end{array}$ & PAULA & $\begin{array}{l}\text { Crianças pequenas - dois anos - no ciberespaço: } \\
\text { interatividade possivel? }\end{array}$ & UnB \\
\hline $\begin{array}{l}2010 \\
\text { (D) }\end{array}$ & GOMES & $\begin{array}{l}\text { Desenvolvimento de atividades pedagógicas para a } \\
\text { educação infantil com a lousa digital interativa: uma } \\
\text { inovação didática. }\end{array}$ & UNICAMP \\
\hline $\begin{array}{c}2011 \\
\text { (D) }\end{array}$ & SILVA & $\begin{array}{l}\text { O som da integração das tecnologias digitais de } \\
\text { informação e comunicação ao currículo: a rádio na } \\
\text { Internet - voz, poder \& aprendizagem. }\end{array}$ & PUC-SP \\
\hline ANO & AUTOR & TITULO & INSTITUIÇÃO \\
\hline $\begin{array}{c}2012 \\
(\mathrm{D})\end{array}$ & SENTANIN & $\begin{array}{l}\text { Viabilidade da implementação de computadores na } \\
\text { primeira etapa da educação básica em uma rede pública } \\
\text { municipal do interior de São Paulo. }\end{array}$ & UNESP \\
\hline $\begin{array}{c}2013 \\
(\mathrm{D})\end{array}$ & CAMARGO & $\begin{array}{l}\text { A educação infantil teclando e navegando pelas } \\
\text { tecnologias da informação. }\end{array}$ & UNICAMP \\
\hline $\begin{array}{c}2013 \\
(D)\end{array}$ & CANASSA & $\begin{array}{l}\text { Infância, TIC e brincadeiras: um estudo na visão } \\
\text { de profissionais da educação infantil - desafios da } \\
\text { geração homo zappiens. }\end{array}$ & UNOESTE \\
\hline $\begin{array}{c}2013 \\
(\mathrm{D})\end{array}$ & GALEB & $\begin{array}{l}\text { A tecnologia digital na infầncia: investigando o Projeto } \\
\text { Kidsmart nos centros municipais de educação infantil } \\
\text { de Curitiba. }\end{array}$ & UFPR \\
\hline $\begin{array}{c}2013 \\
\text { (D) }\end{array}$ & SILVA & $\begin{array}{l}\text { Os recursos geotecnológicos como possibilidade } \\
\text { pedagógica na educação infantil. }\end{array}$ & UFSM \\
\hline $\begin{array}{c}2014 \\
(\mathrm{~T})\end{array}$ & FERREIRA & $\begin{array}{l}\text { A cultura lúdica das crianças contemporâneas na } \\
\text { 'sociedade multitela': o que revelam as 'vozes' de } \\
\text { meninos e meninas de uma instituição de educação } \\
\text { infantil. }\end{array}$ & UFSC \\
\hline $\begin{array}{l}2014 \\
(\mathrm{D})\end{array}$ & MACHADO & $\begin{array}{l}\text { Tablets na educação infantil: tecnologia em sala de aula } \\
\text { e seus benefícios para o processo de alfabetização. }\end{array}$ & UNISINOS \\
\hline $\begin{array}{l}2014 \\
(\mathrm{D})\end{array}$ & MULLER & $\begin{array}{l}\text { Crianças na contemporaneidade: representações e usos } \\
\text { das tecnologias móveis na educação infantil. }\end{array}$ & UFSC \\
\hline $\begin{array}{l}2014 \\
(\mathrm{D})\end{array}$ & NASCIMENTO & $\begin{array}{l}\text { As mídias digitais como instrumentos culturais no } \\
\text { desenvolvimento infantil. }\end{array}$ & PUC-GO \\
\hline $\begin{array}{c}2015 \\
(\mathrm{~T})\end{array}$ & ANJOS & $\begin{array}{l}\text { Tatear e desvendar: um estudo com crianças pequenas e } \\
\text { dispositivos móveis. }\end{array}$ & UFAL \\
\hline $\begin{array}{c}2015 \\
(\mathrm{~T})\end{array}$ & GOMES & $\begin{array}{l}\text { Avaliação do programa "Um Computador por Aluno" } \\
\text { (PROUCA) sob a óptica do modelo CIPP. }\end{array}$ & UFC \\
\hline $\begin{array}{l}2015 \\
(\mathrm{D})\end{array}$ & LIMA & $\begin{array}{l}\text { Num mundo de selfies: a fotografia como recurso } \\
\text { pedagógico para educação infantil. }\end{array}$ & UFPR \\
\hline $\begin{array}{l}2015 \\
(\mathrm{D})\end{array}$ & MENEGUZZO & $\begin{array}{l}\text { O brincar na educação infantil: a influência das } \\
\text { tecnologias digitais móveis no contexto da brincadeira. }\end{array}$ & UCS \\
\hline $\begin{array}{l}2015 \\
(\mathrm{D})\end{array}$ & SILVA & $\begin{array}{l}\text { Manifestações de conteúdos televisivos nas culturas } \\
\text { infantis e interpretações das professoras no contexto pré- } \\
\text { escolar. }\end{array}$ & UNESP \\
\hline $\begin{array}{c}2016 \\
\text { (D) }\end{array}$ & VASCONCELOS & $\begin{array}{l}\text { Modos de participação e apropriação da cultura: vida, } \\
\text { escola e mídia na educação infantil do campo. }\end{array}$ & UNICAMP \\
\hline
\end{tabular}


Observou-se que muitas dessas pesquisas não salientavam dados importantes em seus resumos, a exemplo da metodologia, do referencial teórico ou da faixa etária dos pesquisados no estudo. Esse fato dificultou a análise, necessitando de uma leitura mais rigorosa de todo o contexto da pesquisa, para encontrar esses dados que ficaram obscuros no texto. Um exemplo disso foi uma pesquisa incluída na revisão que se referia à literatura infantil e as tecnologias, entretanto, teve que ser excluída posteriormente à leitura de seu contexto, por se tratar de um estudo com crianças do $1^{\circ}$ ano do Ensino Fundamental.

Alguns outros trabalhos estavam com datas de defesa divergentes entre a base de dados no site e o próprio texto virtual, assim como em outros, constava a definição do tipo de pesquisa (tese ou dissertação) de forma equivocada. Esses dilemas dificultaram o percurso da pesquisa, pelo maior tempo disposto na leitura criteriosa em vista da autenticidade dos dados.

$4^{a}$. Análise e categorização das pesquisas: Após a seleção dos trabalhos que se enquadraram nos propósitos desta pesquisa, foi realizado o refinamento dos dados coletados, com análise aprimorada para a classificação dos textos. Os dados foram examinados com maior cuidado e rigor para a procura das respostas ao problema desta investigação. Esse procedimento exigiu maior habilidade para selecionar o que realmente importa e sintetizar todo o processo construído.

$5^{a}$. Interpretação e apresentação dos resultados: Nesta etapa final da revisão sistemática, houve a interpretação dos resultados, identificando as tecnologias que estavam articuladas à prática pedagógica da infância. Elaborou-se, em seguida, a síntese final para a apresentação dos resultados encontrados, com destaque de perspectivas, prospectivas e avanços de estudos na área.

De acordo com a interpretação dos resultados, a tecnologia mais discutida nas pesquisas foi o computador, que estava relacionado na maioria, aos laboratórios de informática. Outros recursos encontrados foram: internet, tablets, notebooks, laptops, televisões, máquinas fotográficas, filmadoras, microfones, software, lousa digital, entre outros. De modo geral, as demais pesquisas analisaram as TICS, as mídias digitais, os recursos audiovisuais e o uso de dispositivos móveis.

Segundo a problemática de pesquisa, as possibilidades das tecnologias na Educação Infantil abarcam vários benefícios, entre eles, a potencialização do processo de ensino-aprendizagem com oportunidade de desenvolvimento dos requisitos básicos de compreensão e apropriação dos recursos tecnológicos. No entanto, houve muitas adversidades que se relacionaram aos problemas técnicos, a falta de formação profissional e articulação do trabalho pedagógico com o desenvolvido nos laboratórios de informática.

Conforme foi ressaltado, é necessário maior investimento na Educação Infantil, com políticas públicas de valorização profissional e formação continuada que contribua com o desenvolvimento do processo de ensino-aprendizado da infância, aquisição de recursos tecnológicos mais atualizados, maior suporte técnico, entre outros. Isso é necessário, visto que as tecnologias não podem ser utilizadas como um fim em si mesmas, mas para potencializar o processo de ensino-aprendizagem com a produção e construção de conhecimentos

De acordo com a revisão sistemática desenvolvida, as pesquisas relacionadas à temática foram identificadas em maior concentração nas regiões Sudeste (44\%) e Sul (36\%) do Brasil conforme foi demonstrado no Gráfico 2.

${ }^{3}$ As referências e todo o contexto das pesquisas selecionadas estão disponibilizados no site do IBICT. 
Gráfico 2 - Total de pesquisas por região do Brasil (2006-2016)

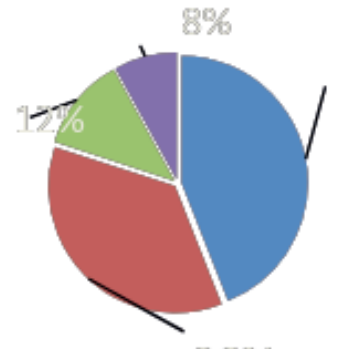

\section{$441 \%$ Sudeste}

-Sul

- Centro-oeste

- Nordeste

Fonte: Elaboração da autora (2017).

Segundo os dados apresentados, houve menor proporção de pesquisas em relação à temática na região Nordeste e nenhuma na região Norte. Esse fato é devido ao processo histórico destas regiões que possuem seus programas de Pós-graduação mais tardios em relação às outras áreas citadas. Conforme o diagnóstico realizado pela CAPES (BRASIL, 2017), existe uma tendência de recuperação dessas regiões em defasagem de instituições, como a região Norte, que aumentou seu número de cursos de Pós-graduação, mesmo com início relativamente tardio.

Foi possível verificar as universidades referentes às pesquisas selecionadas, com 55,5\% de nível federal, com destaque para a Unicamp (SP), que teve o maior número de pesquisas relativas ao assunto discutido (1 tese e 4 dissertações), depois a UFPR (PR), UNESP (SP), UFSC (SC), entre outras. De acordo com dados divulgados pelo INEP (BRASIL, 2015), a Unicamp foi considerada a primeira no ranking nacional das universidades, seguida pela UFRGS e UFMG. Já a USP que é uma universidade de grande renome, não foi acrescentada na lista do INEP, por não participar do Exame Nacional de Desempenho de Estudantes - ENADE, que também é usado pelo MEC para essa avaliação. Contudo, do total de 2.109 IESs avaliadas (BRASIL, 2015), apenas 375 alcançaram o índice satisfatório (17,78\%), conforme o Índice Geral de Cursos - IGC (indicador oficial de qualidade) e CAPES. Esses dados são alarmantes e sugerem a necessidade de investimentos e de políticas públicas que contribuam com a qualificação dos cursos oferecidos em nosso país.

Essa avaliação realizada pelo INEP (BRASIL, 2015), é desenvolvida a cada quatro anos, por meio das informações fornecidas pela Plataforma Sucupira ${ }^{4}$, que considera cinco normas para a avaliação: a proposta do programa, a produção intelectual, o corpo docente, os discentes e a inserção social. Os dados são utilizados também, pelas agências de fomento nacionais e internacionais, bem como para uma agenda de redução de desigualdades entre as regiões brasileiras, entre as áreas do conhecimento, assim como contribuem com os estudantes para decidirem sobre seus cursos futuros.

Ao observar as pesquisas com maior detalhe, foram encontradas 80\% (25) de dissertações, enquanto apenas 19,2\% (5) de teses, sendo que o maior número de publicações foi constatado no ano de 2015. Houve também, maior concentração de pesquisas nos anos de

"É uma importante ferramenta para disponibilizar com mais transparência informações, processos, análises, avaliações como base de referência do Sistema Nacional de Pós-Graduação (SNPG). Disponível em: <https://sucupira.capes.gov.br/sucupira/\#>. Acesso em: 20 set. 2017. 
2007 e posteriormente em 2013 e 2014, com um queda no ano de 2016. Segundo a CAPES (BRASIL, 2017), houve um crescimento de 25\% da Pós-graduação nacional nos últimos quatro anos e em consequência disso, o aumento do número de publicações, sendo o curso de mestrado profissional, o que mais cresceu (77\%), depois o doutorado (23\%) e o mestrado acadêmico (17\%). Entretanto, existe uma carência de cursos na área das tecnologias voltadas para a Educação Infantil, o que sugere a necessidade de repensar e fomentar pesquisas no campo dessa investigação.

Em relação aos cursos de Pós-graduação, 80\% dos trabalhos foram na área de Educação e as outras pesquisas se concentraram em áreas como: Engenharia Elétrica (MACHADO, 2007), Psicologia (OLIVEIRA, 2007), Tecnologia (MACHADO, 2009), Geomática (SILVA 2013) e Gestão Educacional (MACHADO, 2014). Em relação às metodologias, todas foram de abordagem qualitativa com mais de 50\% relativas à pesquisa-intervenção, que vêm crescendo no meio acadêmico. As demais pesquisas se dividiram em estudos de casos, pesquisas etnográficas, grupos focais, entre outras. Algumas pesquisas focaram em oficinas, outras, em sequência didática, elaboração e avaliação de software, introdução de AVA, análise de rádio na internet. A coleta dos dados foi realizada de variadas formas que são: análise documental, entrevistas, observação participante, questionários, diários de campo e utilização de meios tecnológicos variados no processo investigativo. Os referenciais teóricos que se destacaram foram: Vygotsky, Piaget, Freire, Lévy, Kenski, Belloni, Moran, Thiollent, entre outros.

Por meio desta investigação, compreendeu-se que a relação entre o computador e a prática educativa infantil se realizou nos laboratórios de informática, na maioria das pesquisas. Foram muitos os benefícios encontrados, entre eles, a oportunidade de compreender e apropriar dos saberes necessários para a utilização das tecnologias, possibilitando o letramento digital, bem como crescimento do interesse, interação e do trabalho colaborativo. No entanto, precisa estar vinculado a uma proposta pedagógica bem planejada. Para tanto existe a importância da qualificação profissional para ampliar as possibilidades da utilização dos recursos digitais, visto que estão cada vez mais próximos das novas gerações, em um trabalho de inclusão digital tanto das crianças, quanto dos profissionais.

Em relação aos limites encontrados nas pesquisas no ambiente escolar, notou-se que não há integração do trabalho desenvolvido nos laboratórios de informática com as aulas do docente, dificuldades para o suporte técnico e a aquisição de recursos mais atuais,

com a rede de Internet, exigindo a procura de soluções alternativas e a consolidação de políticas públicas de incentivo a esses processos, assim como maior dos jogos e brincadeiras essenciais na cultura infantil.

\section{Considerações}

Este artigo teve o propósito de destacar os resultados de uma pesquisa de abordagem qualitativa, desenvolvida sobre as possibilidades e os limites das tecnologias na Educação Infantil, a partir de uma revisão sistemática de teses e dissertações desenvolvidas nos anos de 2006 a 2016. O estudo se desenvolveu por meio de uma análise de forma exploratória e descritiva no banco de dados do Instituto Brasileiro de Informação em Ciência e Tecnologia - IBICT. No entanto, um dos fatores limitantes para o desenvolvimento deste estudo foi a carência observada em relação às pesquisas que discutiam as tecnologias referentes à Educação Infantil, a alguns problemas de ordem estrutural e de falha em algumas publicações, ampliando o tempo despendido para a seleção dos trabalhos. 
Por meio desse estudo, foi possível verificar que as tecnologias proporcionam muitos benefícios às práticas educativas da infância, desde que sejam bem articuladas e de acordo com as necessidades infantis. E os limites que permeiam esse processo são muitos também, o que sugere a qualificação profissional por meio da formação continuada ou permanente, que de forma colaborativa auxilie aos profissionais à lidarem com os desafios surgidos na educação da infância. Entretanto, são necessárias outras mudanças também nas estruturas físicas das instituições, nos currículos, com maiores investimentos em recursos e na valorização profissional.

A partir deste estudo, foi possível elencar novos propósitos de pesquisas como análise dos desafios tecnológicos e das políticas públicas desenvolvidas nas escolas, bem como estudo de protótipos, de aplicativos ou recursos que possam contribuir com o processo de ensino-aprendizagem infantil, entre outras perspectivas de pesquisas que possam fomentar estudos nesse campo do conhecimento.

\section{Referências}

BRASIL. Referencial Curricular Nacional para a Educação Infantil. Vol. 1. Brasília: MEC,SEF, 1998. Disponível em: <http://portal.mec.gov.br/seb/arquivos/pdf/rcnei_vol1.pdf>. Acesso em: 12 jul. 2016.

BRASIL. Lei n 12 796, de 04 de abril de 2013. Altera a Lei n 9 394/96. Brasília: 2013. Disponível em: <http:// www.planalto.gov.br/ccivil_03/_Ato 2011-2014/2013/Lei/L12796.htm>. Acesso em: 15 mai. 2016.

BRASIL. Conselho Nacional de Educação. Resolução n. 1/2006. Institui Diretrizes Curriculares Nacionais para o Curso de Graduação em Pedagogia, licenciatura. 2006a. Disponível em: <http://portal.mec.gov.br/cne/arquivos/pdf/rcp01_06.pdf>. Acesso em: 6 jul. 2017.

BRASIL. Lei n. 11.274, de 6 de fevereiro de 2006. Altera a redação e estabelece as diretrizes e bases da educação nacional, dispondo sobre a duração de 9 (nove) anos para o Ensino Fundamental. Diário Oficial da União, Brasília, 7 fev. 2006c. Disponível em: <http://www. planalto. gov.br/ccivil_03/_ato2004-2006/2006/lei//11274.htm>. Acesso em: 9 fev. 2016.

BRASIL. Lei n. 11.494, de 20 de junho de 2007. Regulamenta o Fundo de Manutenção e Desenvolvimento da Educação Básica e de Valorização dos Profissionais da Educação - FUNDEB. Diário Oficial da União, Brasília, 21 jun. 2007. Disponível em: <www.planalto.gov.br/ccivil_03/_ato2007-2010/2007/lei/l11494.htm>. Acesso em: 11 mar. 2017.

BRASIL. Programa Nacional de Tecnologia Educacional - Prolnfo. Brasília: MEC, 2016. Disponível em: <http://portal.mec.gov.br/proinfo/proinfo>. Acesso em: 14 set. 2016.

BRASIL. Avaliação da CAPES aponta crescimento da pós-graduação brasileira. CAPES, MEC: 2017. Disponível em: <http://www.capes.gov.br/sala-de-imprensa/noticias/8558-avaliacao-da-capes-aponta-crescimento-da-pos-graduacao-brasileira>. Acesso em: 20 set. 2017.

BRASIL. Índice Geral de Cursos (IGE). INEP, MEC: 2017. Disponivel em: <http://portal.inep. 
BRASIL. Centro de Estudos sobre as Tecnologias da Informação e da Comunicação (Cetic br). Pesquisa. 2017. Disponível em: <http://cetic.br/pesquisa/domicilios/>. Acesso em: 10 jul. 2017.

GIL, Antonio C. Métodos e técnicas de pesquisa social. 6ª ed. São Paulo: Atlas, 2008.

IMBERNÓN, Francisco. Formação permanente do professorado: novas tendências. São Paulo: Cortez, 2009.

KENSKI, Vani M. Educação e tecnologias: o novo ritmo da informação. 4. ed. Campinas, SP. Papirus, 2008

LOPES, A. F.; et al. O desafio do uso das TICs na educação infantil. Revista Pandora Brasil, $n^{\circ}$ 34, Pernambuco, UFPE, set. 2011, p. 170-184.

JUPPE, Nádia. Tecnologias nas instituições de Educação Infantil: limites e possibilidades 2004. Dissertação (Mestrado) - Universidade Federal de Santa Catarina, Florianópolis, 2004.

MORAN, José M.; MASETTO, Marcos T:; BEHRENS, Marilda A. Novas tecnologias e mediação pedagógica. 14. ed. Campinas, SP. Papirus, 2008.

SAMPAIO, Rosana F:; MANCINI, Marisa C. Estudos de revisão sistemática: um guia para síntese criteriosa da evidência científica. Revista Brasileira de Fisioterapia, v. 11, n. 1, p. 83-89, jan./fev. 2007. Disponivel em: <http://www.scielo.br/pdf/\%0D/rbfis/v11n1/12.pdf >. Acesso em: 6 jul. 2017

SODRÉ, Muniz. Reinventando a Educação: diversidade, descolonização e redes. Petrópolis/ RJ: Vozes, 2012.

TAPSCOTT, Don. A Hora da Geração Digital: como os jovens que cresceram usando a internet estão mudando tudo, das empresas ao governo (tradução de Marcello Lino). Rio de Janeiro: Agir Negócios, 2010.

VYGOTSKY, Levy; LURIA, A.; LEONTIEV, A. Linguagem, Desenvolvimento e Aprendizagem 14. ed. São Paulo: Ícone, 2016. 